\title{
ARTIGOS
}

\section{RESIGNAÇÃO? PRÁXIS E POLÍTICA NA TEORIA CRÍTICA TARDIA DE THEODOR W.}

\section{ADORNO RESIGNATION? PRAXIS AND POLITICS IN THEODOR W. ADORNO'S LATE CRITICAL THEORY}

Amaro Fleck* amarofleck@hotmail.com

RESUMO $A$ teoria crítica tardia de Theodor $W$. Adorno é considerada por muitos como quietista e resignada. O presente artigo busca questionar tal veredito por meio de uma análise tanto do diagnóstico de época, feito pelo autor, quanto da relação entre teoria e práxis delineada nas obras do periodo tardio do pensador frankfurtiano. Sugere-se que, em vez de resignada, a teoria crítica de Adorno está engajada seja nos processos de resistência à barbárie latente, seja nas melhorias pontuais que poderiam ser conseguidas no interior da ordem vigente. Tal engajamento, no entanto, não significa um abrandamento da tese de que a possibilidade de emancipação estaria bloqueada.

Palavras chave: Theodor W. Adorno, teoria crítica, teoria e práxis, filosofia política contemporânea.

Abstract: Theodor W. Adorno's late critical theory is often regarded as quietist and resignated. This article seeks to question this verdict through an analysis of both the diagnosis of time made by the author as of the relation-

1 O presente artigo é uma versão levemente modificada do primeiro capítulo de minha tese de doutorado, intitulada Theodor W. Adorno, um crítico na era dourada do capitalismo, escrita sob orientação do Prof. Alessandro Pinzani, a quem agradeço, assim como aos professores que participaram da banca de defesa: Emiliano Gambarotta, Eduardo Neves, Alexandre Vaz, Denilson Werle e Marta Rios.

* Universidade de Lavras. Artigo recebido em 13/07/2015 e aprovado em 15/01/2016. 
ship between theory and praxis outlined in Frankfurtian thinker's late works. It is suggested that instead of resigned, Adorno's critical theory is engaged either in processes of resistance to the latent barbarism, whether in specific improvements that could be achieved within the existing order. This engagement, however, does not mean a mitigation of the thesis that the possibility of emancipation would be blocked.

Keywords: Theodor W. Adorno, critical theory, theory and praxis, contemporary political philosophy.

A objeção mais comum e repetida à teoria adorniana consiste na afirmação de que ela é demasiado pessimista e, por conseguinte, quietista e resignada. Tal crítica parece beirar a unanimidade, sendo aceita por teóricos os mais distintos (e distantes). Para o historiador polonês Leszek Kolakowski, crítico ferrenho do marxismo (que acreditava que o totalitarismo stalinista era sua consequência lógica), a obra de Adorno "não é uma expressão de revolta universal, mas de desamparo e desespero" (Kolakowski, 1978, p. 396). Georg Lukács, durante a fase em que esteve alinhado à ortodoxia do partido comunista soviético, afirmou que "parte considerável da nata da inteligência alemã, inclusive Adorno", habitava o "Grande Hotel Abismo", "um belo hotel, provido de todo conforto, à beira do abismo, do nada, do absurdo. E o espetáculo diário do abismo, entre refeições ou espetáculos comodamente fruídos, só faz elevar o prazer desse requintado conforto" (Lukács, 2000, p. 18) ${ }^{1}$. Mesmo Jürgen Habermas, o mais conhecido entre os sucessores da teoria crítica, afirma que, se em "1931, Adorno ainda fala categoricamente de 'atualidade da filosofia', porque confia a ela um acesso à realidade, não afirmativo, que em meio a vestígios e escombros garanta a esperança de atingir a realidade certa e justa", em 1966, com a Dialética negativa, ele "deixa de lado essa esperança" (Habermas,

1 Ao que Adorno respondeu, em uma anotação que só foi publicada postumamente: "Lukács me censurou com uma anedota estúpida (esta estupidez pertence à regressão geral, a qual hoje se toma por revolucionária), a qual diz que eu me estabeleci em um hotel de luxo na beira do abismo. Isto é acolhedor; o abrigo de Chaplin em Em busca do ouro não seria a pior alegoria para meu pensamento. Lukács caiu no abismo e não sabe como pode se salvar; ele nem sequer está aqui porém rasteja, velho, abalado como uma das personagens de Beckett, com a qual ele fica indignado, lá em baixo. Onde devo então morar? No bolor da segurança? Prefiro meu pouco seguro hotel de luxo. Seu luxo não é senão a sorte (Glück) de manifestar a extrema negatividade; e mesmo isto é invejado." (Adorno, Gr II, p. 36) 
2012 , p. 643)2 . Não creio que tais afirmações façam justiça à teoria adorniana ${ }^{3}$. Segundo elas, a teoria de Adorno seria apenas a representação do desespero, da falta de esperança e, por conseguinte, um mero lamento resignado. O exato oposto da visão que o próprio autor tinha de suas teorias: "considero que minha postura, assim como a de Horkheimer, mantém-se totalmente o contrário da resignação" (Adorno, KTP, p. 400).

No entanto, em primeiro lugar, é preciso reconhecer que há, nas críticas dos autores recém-evocados, certo teor de verdade ou, ao menos, que estão mais próximas do texto adorniano do que a tese contrária, a saber: que o filósofo frankfurtiano seria um inveterado otimista, crente na inevitabilidade dos progressos humanos ou na resolubilidade dos problemas existentes. Há uma tendência na literatura filosófica contemporânea de tentar, a todo custo, "salvar" os autores das objeções mais usuais a partir da defesa de que o filósofo em questão nunca afirmou suas teses mais conhecidas e, sim, as opostas. Assim, o filósofo defensor do estado absoluto torna-se o democrata preocupado com a salvaguarda dos direitos individuais; o apologeta do livre mercado passa a ser visto como promotor do bem-estar e preocupado com a melhoria dos serviços públicos universais, etc. No entanto, é preciso resistir a essa tentação. Definitivamente, Adorno não foi um otimista. Ele não acreditava ter boas razões para nutrir esperanças de que o mundo estava progredindo rumo a um estágio mais justo e feliz. Mas o que motiva tal desesperança? E, se como proponho, é um equívoco considerar Adorno um teórico resignado, quais as perspectivas de mudança que, segundo ele, ainda restam? É possível ainda uma práxis transformadora? Estas são as questões que gostaria de tentar responder neste capítulo. Para tanto, o percurso a ser percorrido se inicia com a análise do que faz, sempre segundo o frankfurtiano, com que a sociedade moderna seja nãoemancipada e seus membros não possam ser considerados sujeitos livres (1); a seguir, examina-se por que o caminho para a emancipação estaria bloqueado (2); neste momento, a argumentação principal é interrompida para uma breve digressão sobre a relação conflituosa entre Adorno e o movimento estudantil de sua época (3). Digressão necessária para se entender as considerações sobre

2 Não pretendo, no presente trabalho, analisar com profundidade a leitura e as objeções de Habermas à teoria de Adorno. Limito-me apenas a mencionar tal interpretação como uma daquelas que se contrapõe a interpretação que aqui ofereço. Para uma análise crítica das objeções habermasianas, sugiro a leitura de Duarte (1997), Silva (2005), Hullot-Kentor (2006), Blasco (2010) e Petry (2011). Para uma comparação entre a crítica e o diagnóstico de Adorno e Habermas, indico a obra de Cook (2004).

3 A questão do posicionamento político, das esperanças de transformação e dos limites das mudanças sociais possíveis na obra tardia de Adorno tem recebido, nos últimos anos, atenção redobrada, em parte devido a alguns materiais inéditos que vieram à tona (cursos, cartas e manuscritos), em parte porque a postura de Adorno, cética tanto ante a alternativa revolucionária de transformação social quanto ante os potenciais emancipadores da política democrática eleitoral, parece especialmente sedutora nos últimos tempos. Merecem especial destaque, no que tange ao assunto, os artigos de Cook (2004b), Wilding (2009), Juárez (2012) e Freyenhagen (2014). 
a relação entre teoria e práxis, as críticas que Adorno tece ao ativismo e os limites que o engajamento político deve saber respeitar (4). Na conclusão (5), por fim, defendo que a obra tardia de Adorno não deve ser vista como resignada, nem como uma recusa veemente a qualquer engajamento prático, mas sim como uma teoria consciente das possibilidades e impossibilidades inerentes ao seu tempo.

\section{De que é preciso se emancipar?}

Se, como será visto, o caminho da emancipação está bloqueado, ou ao menos assim pensava Adorno, é porque não apenas há obstáculos que impedem os humanos de serem livres, de se autodeterminarem, como também há obstáculos que impedem que eles retirem esses obstáculos. Além disso, se a liberdade consiste, de acordo com ele, na capacidade de criticar e transformar as situações (Cf. Adorno, DN, p 191, nota), o estado de não-liberdade é justamente aquele no qual a situação vigente é todo-poderosa e o indivíduo, impotente. Resulta disso um paradoxo, o qual, infelizmente, encontra-se na realidade e não meramente na teoria, segundo o qual para transformar a má realidade já seria preciso a liberdade da qual ainda não se dispõe. $\mathrm{O}$ mundo no qual voluntarismo e boa vontade servem para algo já seria um mundo liberto. Já na situação falsa, toda tentativa de mudança parece de antemão condenada ao fracasso. Contudo, antes de lidar com a questão do que bloqueia o caminho para a emancipação, convém analisar o que faz com que os humanos sejam considerados por Adorno como indivíduos não-livres na sociedade vigente.

"Originalmente, emancipação designava a libertação do escravo que, não tendo mais um senhor, tinha acesso à autonomia. Sempre nos emancipamos em relação a alguma coisa, ou seja, trocamos a heteronomia pela autonomia, tornando-nos nossos próprios senhores" (Jappe, 2013, p. 29-30). Se não estamos emancipados, portanto, é porque não somos nossos próprios senhores. Mas se tampouco somos escravos, ou ao menos assim pensamos sobre nossa condição, de que é preciso se emancipar? No caso específico de Adorno, os seres humanos não são livres, autônomos, porque organizam a sociedade de um modo cego, pois estão dominados pelo seu próprio modo de produção, pela forma de racionalidade que lhe é inerente e pelo modo como isso molda suas próprias subjetividades. Em outras palavras, Adorno segue Marx na crença de que aquilo que impede a autonomia dos seres humanos é o capitalismo. "Para além da cabeça dos indivíduos formalmente livres, a lei do valor se impõe. Eles são desprovidos de liberdade, de acordo com a intelecção de Marx, enquanto os seus [i.e. da lei do valor] executores involuntários" (Adorno, DN, p. 219*). É importante frisar desde já que por capitalismo não se entende aqui simplesmente um sistema baseado na propriedade privada dos meios de produção, mas 
sim um tipo muito específico de civilização cuja subsistência depende de uma forma de organização econômica dinâmica, em contínuo crescimento, e que não se encontra sob domínio direto e consciente dos homens. Não se trata, por conseguinte, de supor a existência de uma estrutura econômica que determina unilateralmente as demais esferas da sociedade; mas sim de um processo intrassocial cuja expansão coloca permanentemente em risco as relações sociais não submetidas diretamente à sua dinâmica inerente, um processo que abocanha ou tenta abocanhar tudo aquilo que ainda não se encontra em seu domínio imediato. Este processo é caracterizado não apenas pela necessidade de crescimento econômico desenfreado, mas também por uma mentalidade capaz de equiparar (e portanto quantificar) coisas diferentes, aniquilando as qualidades dos objetos e, assim, fazendo violência a eles. Ademais, é caracterizado ainda por uma constante inversão de meios e fins, de modo que, no âmbito econômico, a produção deixa de ser feita para suprir carências (tornando-se sua própria finalidade), assim como, no âmbito epistêmico, a classificação deixa de ser um meio para o conhecimento, uma vez que este é reduzido a ela.

Embora Adorno faça uma crítica radical da sociedade, isto é, mostre que o sofrimento desnecessário que ela provoca não é contingente, mas intrínseco à sua própria estrutura e que portanto só uma mudança igualmente radical seria capaz de combater a causa, e não o sintoma, que provoca tais sofrimentos, isto não o torna um revolucionário ou um defensor da revolução. Ou, pelo menos, na forma como esta é comumente entendida (isto é, como a tomada violenta dos mecanismos de decisão, do poder). Em uma passagem da Dialética negativa, ele afirma que "aquele que se embriaga como espectador com batalhas, revoluções e catástrofes silencia quanto a se a libertação, da qual ele fala de modo burguês, não deveria se libertar destas categorias" (Adorno, DN, p. 293). Sua recusa se deve, por um lado, ao fato de que o ideal revolucionário (ao menos o moderno) é profundamente burguês, em especial no que toca a sua grandiloquência; e por outro, a que o processo de libertação deveria já antecipar as práticas libertas que tenta trazer à luz, em vez de repetir a violência contra a qual atua.

\section{O bloqueio da emancipação}

"A filosofia, que um dia pareceu ultrapassada, mantém-se viva porque se perdeu o instante de sua realização" (Adorno, DN, p. 11). Esta é a frase que dá início à Dialética negativa. Ela não apenas afirma que a filosofia perdeu seu instante de realização, mas que se mantém viva justamente por causa disso. Refletir sobre seu próprio fracasso em realizar-se torna-se, então, sua principal tarefa. Mas o que seria a realização da filosofia? A rigor, nada mais do que a instauração de uma ordem social racional, uma ordem na qual todos estariam 
livres da dominação arbitrária, seja esta proveniente do poder político, seja do poder religioso ou do poder econômico. De acordo com o filósofo frankfurtiano, tal libertação dessas formas de dominação foram possibilidades reais em alguns momentos específicos da história. Por exemplo, quando Marx e Engels clamavam à prática revolucionária no Manifesto comunista, existia uma real possibilidade de mudança, de emancipação, mas quando os estudantes faziam o mesmo, em 1968, esta possibilidade era, ao menos segundo ele, ilusória. Cito Adorno:

Hoje só se pode filosofar negando a tese marxista de que a reflexão está superada. Esta tese pensou a possibilidade da transformação do mundo como algo que está presente aqui e agora. Só por teimosia se poderia supor hoje esta possibilidade igual à do tempo de Marx. O proletariado ao qual Marx se dirigia não estava todavia integrado, se empobrecia a olhos vistos, e o poder social não dispunha dos meios com os quais sair em uma situação de emergência. A filosofia, o pensamento simultaneamente coerente e livre, se encontra em uma situação completamente diferente. (Adorno, WnP, p. 469) ${ }^{4}$

Nesta citação, Adorno é muito claro quanto aos dois aspectos cuja transformação fez a possibilidade da emancipação desaparecer. Por um lado, o proletariado se integrou à sociedade capitalista, por outro, o poder social tem então mais meios para se safar em uma situação de emergência, ou melhor, mais instrumentos, tanto físicos quanto psicológicos, para assegurar sua dominação e permanência. Gostaria de tratar esses dois tópicos de forma mais pormenorizada, pois sem a análise deles é impossível entender a situação na qual o frankfurtiano se encontrava, em especial sua distância em relação ao ativismo e sua defesa intransigente da teoria como o refúgio atual da liberdade.

\subsection{Integração do proletariado}

Para Adorno, a crença de Marx no potencial revolucionário do proletariado não era uma quimera. Tratava-se, na época, de um diagnóstico preciso. Os trabalhadores, no começo do século XIX, estavam em uma situação muito particular em que, ao mesmo tempo, participavam e não participavam da sociedade:

A teoria de Marx se constitui essencialmente na suposição (...) da extraterritorialidade social do proletariado, isto é, ela se baseia em que o proletariado, por um lado, não apenas reproduz toda a vida da sociedade por meio da venda da mercadoria força de trabalho, porém que ele também toma parte dessa sociedade na medida em que recebe um mínimo. (...) Eles [os proletários] (...) estavam lá dentro da sociedade, na qual eles ajudavam a providenciar [o necessário] para sua vida, mas em um sentido semelhante mais pensar como Marx pensou, a saber, que a revolução estava iminente - simplesmente porque, por um lado, o proletariado em sua época não estava integrado na sociedade burguesa e, por outro, a sociedade burguesa não possuía ainda os vastos instrumentos de poder, tanto instrumentos físicos de poder quanto também instrumentos psicológicos em sentido amplo, que esta tem agora" (Adorno, VüND, p. 71). 
estavam fora, como se pode dizer na sociedade antiga de uma extraterritorialidade dos escravos para com a sociedade, visto que os escravos não estavam incluídos em seu conceito de pessoas, como sabem, ou que só sob grandes restrições ela permitiu esta participação na sociedade. (Adorno, PETG, p. 53-54)

No entanto, a situação vigente, no final dos anos sessenta, era completamente diferente:

Os fenômenos que hoje observamos são, em primeiro lugar, não outra coisa senão que o proletariado está integrado, isto é, que o proletariado, no âmbito da sociedade burguesa, reproduz sua vida para além do mínimo, que as antigas diferenças mais notórias e mais drásticas entre um proletário e um burguês, um assim chamado proletário de colarinho branco, por conseguinte, um assalariado, tornam-se cada vez menores, e que o proletariado sobretudo perdeu o [aspecto] explosivo de ser uma força inconciliável com a sociedade, como ele foi outrora, uma vez que foi arrebatado para dentro do campo de força do desenvolvimento capitalista. (Adorno, PETG, p. 54)

Ou seja, havia, na época do Manifesto comunista, uma extraterritorialidade do proletariado que o tornava "uma força inconciliável com a sociedade". Ao mesmo tempo em que participava da vida social, sendo, por assim dizer, quem assegurava a reprodução material da sociedade, ele também ficava fora das vantagens da vida social, permanecia um corpo estranho à sociedade na medida em que não era plenamente membro dela. Por uma série de motivos isso não é mais assim. Ao menos é isso o que a tese da integração do proletariado afirma. Segundo tal tese, a ideia de que os trabalhadores não têm nada a perder senão seus grilhões deixou de ser verdadeira, uma vez que houve uma série de melhorias na vida deles que fez com que pudessem participar da sociedade de forma ativa. A tendência ao empobrecimento contínuo da classe trabalhadora, diagnosticada por Marx, não só não foi verificada, como uma tendência oposta prevaleceu, de forma que os assalariados, ao menos nas partes mais desenvolvidas do mundo, viram sua situação material melhorar de forma considerável. Sem dúvida é difícil indicar o momento exato em que se dá essa integração, principalmente porque não se trata de uma mudança súbita, mas de um evento progressivo, de uma tendência de longo prazo. Adorno, no entanto, oferece algumas pistas. Ele comenta que o filósofo inglês Herbert Spencer, em seus Princípios da sociologia, publicado em 1876, foi o primeiro a diagnosticar a integração da sociedade (Cf. Adorno, IS, p. 90) ${ }^{5}$. Assim é possível afirmar que o momento decisivo, por assim dizer, deu-se entre a década de 40

5 "Aqui se localiza - para mencionar algo - a tendência à integração da sociedade, diagnosticada pela primeira vez por Spencer: o fato de a rede de socialização ser tecida em malhas cada vez mais densas, incorporando por essa via progressivamente mesmo aqueles que se situavam exteriormente à sociedade burguesa, ou melhor, se situavam meio fora da sociedade burguesa, tal como o proletariado industrial durante as décadas de trinta e quarenta do século XIX" (Adorno, IS, p. 90). 
e o começo do último quartel do século XIX ${ }^{6}$. A partir de então, segundo Adorno, não haveria mais uma força organizada que fosse hostil à ordem social, um grupo capaz de colocar a situação vigente em risco, ao menos nos países do capitalismo avançado ${ }^{7}$. (Contudo, a afirmação da integração do proletariado não significa uma superação da cisão de classe. As classes seguem existindo e contrapondo-se umas às outras, apesar de nenhuma delas apresentar uma extraterritorialidade ou ser uma força inconciliável com a sociedade). Neste momento, ao menos, importa salientar que a integração do proletariado representa uma drástica mudança na primazia da prática frente à teoria, afirmada, por exemplo, na tão citada décima primeira tese de Marx sobre Feuerbach: "os filósofos apenas interpretaram o mundo de diferentes maneiras; o que importa é transformá-lo" (Marx, 2007, p. 535). Na ausência da possibilidade real de uma transformação, ao menos segundo Adorno, é preciso voltar-se novamente para a interpretação. "A práxis, adiada por um tempo indeterminado, não é mais a instância de apelação contra a especulação satisfeita consigo mesma" (Adorno, DN, p. 11). Na verdade, segundo Adorno, isso pode ser percebido na própria trajetória intelectual de Marx:

As Teses sobre Feuerbach de Marx, por exemplo, não podem ser compreendidas corretamente in abstracto, desvinculadas da dimensão histórica, mas têm seu significado no contexto da expectativa de uma revolução iminente existente em sua época; sem uma tal expectativa, elas degeneram em uma mera fórmula mágica. Que após essa possibilidade dada não se realizar, Marx tenha-se sentado durante décadas no Museu Britânico para escrever uma obra teórica de Economia Política, sem se dedicar efetivamente a tanta práxis assim, isso não é uma mera questão de acaso biográfico, mas expressa também justamente um momento histórico. (Adorno, IS, p. 337)

Mais um indício, por conseguinte, da tese de Adorno de que as precondições necessárias para uma transformação radical da sociedade já não estavam presentes quando Marx escreve $O$ Capital; e de que a falta de tais precondições deve conduzir a um momento em que a teoria tem a primazia.

\subsection{Intensificação da dominação}

A integração do proletariado, no entanto, é apenas um dos elementos que fazem com que o caminho para uma emancipação do capitalismo esteja, aos olhos de Adorno, bloqueada. O outro elemento consiste no fato, já citado, de

6 O que está de acordo com o que relata Piketty: "A partir do último terço do século XIX, os salários enfim começaram a aumentar: a melhora do poder de compra dos trabalhadores se disseminou, o que mudou radicalmente a situação, ainda que a desigualdade extrema tenha persistido e, em certos aspectos, crescido até a Primeira Guerra Mundial" (Piketty, 2014, p. 17).

7 Freyenhagen (Cf. 2014) sugere, diferentemente do que faço aqui, que o momento crucial teria ocorrido entre o final da primeira guerra mundial e a ascensão do fascismo e do stalinismo, momento em que havia uma situação de pouquíssima estabilidade sociopolítica. 
que então "o poder social não dispunha dos meios com os quais sair em uma situação de emergência" (Adorno, WnP, p. 469) ou, mais precisamente, de que "a sociedade burguesa não possuía ainda os vastos instrumentos de poder, tanto instrumentos físicos de poder quanto também instrumentos psicológicos em sentido amplo, que esta tem agora" (Adorno, VüND, p. 71). A especificação de que se trata de instrumentos físicos e psíquicos é valiosa. Por um lado, a ordem burguesa passa a ter, no século XX, uma força repressora organizada suficiente para reprimir qualquer possível motim contra ela. Mais do que isso, com o avanço tecnológico, aqueles que detêm o poder político, os que governam a sociedade, dispõem de armamentos não só capazes de dar fim a uma insurreição, mas também, fato este certamente novo, de aniquilar a própria sociedade, aliás, várias vezes. Adorno sintetiza esse pensamento em uma observação extremamente lúcida: "as barricadas são ridículas contra aqueles que administram a bomba" (Adorno, MzTP, p. 771). Por outro lado, há também a intensificação da dominação psíquica dos indivíduos submetidos à ordem capitalista. Adorno comenta que há uma tendência histórica de internalização dos mecanismos de repressão, os quais deixam de ser meramente exteriores e passam a moldar a própria ordem psíquica dos indivíduos. Talvez o principal mecanismo seja justamente o da indústria cultural, tão estudada por ele. Uma das principais consequências do surgimento da "cultura de massas", não aquela que vem delas, mas sim a que é imposta sobre, é um efeito de acomodação. Com isso a sociedade burguesa é capaz, mais uma vez, de solapar as possibilidades de uma subversão. Novamente, isso não é indiferente para a relação entre teoria e práxis. Ignorar esses dois elementos e precipitar-se em um ativismo, mantendo a primazia da práxis sobre a teoria, ao menos aos olhos do frankfurtiano, redunda no que ele chama de uma pseudoatividade, um tipo de ação irrefletida inconsciente de sua própria inutilidade.

\section{Breve excurso: Adorno e o movimento estudantil}

Antes de ver as críticas que Adorno tece ao ativismo, isto é, a tentativa de se precipitar em uma atividade revolucionária quando não estão dadas as condições necessárias para que esta tenha alguma probabilidade de êxito, convém trazer à tona algumas informações não apenas sobre a relação conflituosa entre o teórico crítico frankfurtiano e o movimento estudantil (cujos participantes frequentavam com assiduidade seus cursos e conferências), mas também sobre o ambiente político alemão em que se deu tal relação.

Adorno se colocava claramente entre os setores mais à esquerda do espectro político, tomando parte entre aqueles que não acreditavam que uma democracia real, com cidadãos livres e não tutelados, pudesse ser alcançada em uma sociedade cuja reprodução material dependia do modo capitalista de produção. 
Apesar de bastante reticente quanto às possibilidades da política eleitoral, ele era um eleitor do Partido Social-Democrata (SPD) e chegou a cogitar escrever uma crítica à guinada conservadora deste no final dos anos 1950, crítica que seria claramente inspirada na Crítica do programa de Gotha, de Marx ${ }^{8}$. O cenário político-eleitoral se deteriora ainda mais ao longo dos anos 60, quando o SPD faz uma grande coalizão com a União Democrata Cristã (CDU), passando da oposição branda para a base de um governo conservador. A falta de horizonte político, ou melhor, o descrédito da política eleitoral coincide temporalmente com o começo da agitação estudantil no não pouco controverso final da década de 60 .

A Guerra do Vietnã, o caso Springer ${ }^{9}$, a visita do Xá da Pérsia ${ }^{10}$, a crise da universidade ${ }^{11}$ e a aprovação das leis de emergência ${ }^{12}$ deram o contorno particular para os conflitos que sacudiram a sociedade alemã, sobretudo depois de 1967. A guinada ao centro do SPD e o consequente desaparecimento da oposição parlamentar abriu espaço para o surgimento de uma oposição extraparlamentar (ApO), a qual foi muito ativa em todo o desenvolvimento das manifestações. A posição de Adorno foi, desde o princípio, um tanto hesitante. Ele era bastante próximo da União Alemã dos Estudantes Socialistas (SDS) e, por conseguinte, da ApO. O principal agitador do movimento estudantil em Frankfurt, Hans-Jürgen Krahl, fazia doutorado em Filosofia sob sua orientação, e Oskar Negt, outro nome importante da ApO, era bastante próximo a ele e ao Instituto. No entanto, o frankfurtiano mostrava grande receio em dar demonstrações públicas de seu apoio, um temor em geral justificado pelo bastante questionável medo de que a teoria crítica fosse instrumentalizada para fins políticos. Mesmo assim, apoiou abertamente a oposição à aprovação das leis de emergência, as-

8 As informações deste capítulo foram, em grande parte, retiradas das biografias de Adorno escritas por Stefan Müller-Doohm (cf. 2009) e por Detlev Claussen (cf. 2008).

9 A campanha anti-Springer questionava o monopólio dos meios de comunicação da Springer Verlag, empresa que tinha um viés claramente conservador (para não dizer reacionário) e que se opôs de forma veemente aos protestos estudantis, desde seu princípio. Depois da cobertura tendenciosa feita pelos meios de comunicação da empresa sobre da tentativa de assassinato de Rudi Dutschke, o principal líder do movimento estudantil de Berlim, Adorno assinou com outros intelectuais um apelo (o qual foi publicado no Die Zeit) cobrando uma investigação sobre tal tentativa de assassinato e sobre a manipulação da opinião pública pelos periódicos da Springer Verlag (cf. Müller-Doohm, 2009, p. 459).

10 No começo de junho de 1967, o Xá da Pérsia fez uma visita à Alemanha ocidental. Os estudantes acusaram o governo alemão de cumplicidade com o regime iraniano, uma ditadura que fazia uso sistemático da tortura. Nos protestos, o estudante Benno Ohnesorg foi morto.

11 O governo alemão propôs uma reforma universitária que, grosso modo, pretendia adequar o ensino às novas exigências do mercado. O movimento estudantil, ao contrário, queria que a reforma ampliasse os espaços democráticos da gestão da universidade, aumentando o poder dos estudantes, além de uma série de outras alterações.

12 As leis de emergência suspendiam uma série de direitos civis caso houvesse um desastre natural, guerra ou insurreição que exigisse uma intervenção mais firme do governo. Houve forte pressão popular contra a aprovação delas. 
sim como era pública a sua simpatia à reforma da Universidade ${ }^{13}$, sua indignação frente à manipulação da opinião pública feita pelos periódicos da Springer Verlag e a forma como a polícia reprimiu a manifestação contra a visita do Xá da Pérsia, que resultou na morte de Benno Ohnesorg. O caso relativo ao Vietnã era mais complicado. Adorno era hostil ao antiamericanismo em geral (em parte devido ao fato de outrora ter encontrado nos Estados Unidos refúgio da barbárie nazista, em parte por consideração e apreço à democracia lá existente, a qual Adorno considerava mais enraizada na sociedade e na consciência do que a democracia europeia em geral e sobretudo a alemã), e ainda mais hostil a qualquer simpatia pelos regimes comunistas, fossem eles alinhados a Moscou ou a Pequim. Como a questão envolvia esses dois elementos, ele evitou dar qualquer apoio às manifestações contra a guerra ${ }^{14}$, como se a omissão não fosse ela própria uma atitude ou posição (que sempre tende a favorecer o lado mais forte), e de certa forma mesmo um assentimento.

A posição de Adorno era bastante clara, e é provável que boa parte dos conflitos entre ele e os estudantes não teriam se sucedido se o movimento estudantil a tivesse compreendido. O frankfurtiano apoiava e apoiaria a ApO enquanto esta fosse consciente de que sua função era, como defendera Habermas (de quem Adorno foi muito próximo em toda esta querela), proclamar a "ausência de uma política que é esclarecida em suas intenções, honesta em seus métodos e progressiva em suas interpretações e ações" (Habermas apud Müller-Dohm, 2009, p. 452-453). Na situação vigente, pequenas reformas poderiam ser obtidas (caso, por exemplo, da revogação das leis de exceção, da reforma da Universidade e mesmo de uma reforma do direito penal ${ }^{15}$ ), e o engajamento deveria se focar nestes pontos se quisesse obter algum sucesso na empreitada de tornar a sociedade algo um pouco melhor. Grosso modo, a isso correspondia o movimento estudantil em sua primeira fase e mesmo no começo da segunda ${ }^{16}$. O entusiasmo de Adorno neste momento é manifesto em um

13 À qual, não obstante, ele tinha certas reservas. Suspeitava que em geral os estudantes queriam tornar seus estudos mais fáceis e argumentava que se muitas práticas arcaicas tinham de desaparecer, outras deviam ser defendidas como refúgios do humano (cf. Müller-Doohm, 2009, p. 455).

14 Embora mencione, no curso sobre Metafísica, de 1965, que o mundo da tortura que tem em Auschwitz seu símbolo continua existindo, que dele se está recebendo os mais terríveis relatos vindos do Vietnã (Cf. Adorno, Me, p. 160). E na Dialética negativa afirme que a tortura e os campos de concentração seguem existindo na Ásia e na África porque "a humanidade civilizada é como sempre desumana em relação àqueles que são estigmatizados por ela de maneira ignominiosa como não-civilizados" (Adorno, DN, p. 238).

15 A reforma do direito penal visava a acabar com a proibição da homossexualidade, a igualar os direitos entre casais heterossexuais e homossexuais, assim como atenuar outros efeitos de tabus sexuais presentes na sociedade no âmbito do direito penal. Adorno dedicou um artigo bastante interessante ao assunto, "Tabus sexuais e o direito hoje" (Cf. Adorno, SRh).

16 Habermas sugere uma divisão dos protestos estudantis em três momentos: no primeiro, havia um movimento pela reforma da Universidade, assim como uma politização geral devido às discussões sobre a Guerra do Vietnã; uma politização mais radical ocorre com os protestos contra a visita do Xá da Pérsia, com a morte de Benno Ohnesorg, com a campanha contra a Springer Press e com a resistência às leis de emergência; a fase final é marcada por uma radicalização ainda maior, na qual foi defendido o uso da ação 
trecho da conferência “Capitalismo tardio ou sociedade industrial?", proferida em abril de 1968:

Só nos tempos mais recentes se fizeram visíveis marcas de uma tendência oposta precisamente nos mais diversos grupos da juventude: resistência contra uma adaptação cega, liberdade com relação aos fins escolhidos racionalmente, aversão ante o mundo como embuste e representação, presença da possibilidade de transformação. (Adorno, SoI, p. 368)

O entusiasmo, no entanto, estava com os dias contados. Já naquele momento, os protestos se radicalizavam e a situação passava a ser vista, por parte dos estudantes, como pré-revolucionária. Agora não se tratava mais de pequenas reformas, mas de ações diretas capazes de provocar o Estado, de resistência ativa e politização contínua. Adorno não seria antipático a uma mudança radical da sociedade, mas acreditava que a situação nada tinha de pré-revolucionária e que tais tentativas estavam fadadas ao fracasso de antemão. Como sabia disto? Por meio da análise da sociedade de seu tempo, por causa dos obstáculos que impediam a mudança. Não havia um grupo antagonista suficientemente forte para colocar o sistema em perigo. Os estudantes podiam querer ser tal grupo, mas estavam longe de conseguir isso. Ademais, os mecanismos de dominação tinham se intensificado a tal ponto que não só fatores externos (a força física repressiva) levavam a uma adaptação resignada, mas também fatores internos (a dominação psíquica feita pela indústria cultural) tornavam tal adaptação desejada. Ignorar isso seria um sinal de desespero. Ademais, os estudos sobre o estado do antissemitismo levado a cabo pelo Instituto mostravam que este estava longe de fazer parte de um passado longínquo, de modo que uma suspensão da ordem tendia a ser regressiva, reavivando o fascismo latente da sociedade alemã, e não progressista, fazendo de tal sociedade uma ordem mais justa e emancipada.

Ainda em junho de 1967, Habermas havia discutido com Rudi Dutschke sobre os rumos da ApO e afirmado que o ativismo vinculado ao voluntarismo que estava se impondo poderiam conduzir a um fascismo de esquerda ${ }^{17}$. Adorno concorda com o diagnóstico de Habermas, em especial por causa da tendência inerente ao movimento de pressionar de forma autoritária ou mesmo violenta pela participação e apoio em suas manifestações. Quando Marcuse objetou a Adorno que o movimento estudantil em questão era uma esquerda

direta e que resultou mesmo na criação de grupos "terroristas" como a RAF (Rote Armee Fraktion [Fração do Exército Vermelho]). Cf. Müller-Doohm, 2009, p. 605-606.

17 Muito tempo depois, quando os democratas cristãos (dentre os quais o então Cardeal Ratzinger) acusaram a Escola de Frankfurt e a teoria crítica como fonte de inspiração para os atos terroristas da RAF, Habermas amenizou seu dito lembrando que o máximo que os amigos de Dutschke fizeram foi jogar tomates, que eles não matavam pessoas. (Cf. Ryan, 2003) 
autêntica, e que portanto não poderia "transformar-se na direita, sem mudar essencialmente sua base social e seu objetivo. No movimento estudantil nada indica uma mudança desse tipo" (Marcuse, 1997, p. 11), Adorno respondeu de forma bastante drástica que a atuação do movimento estudantil:

É discutível de dois pontos de vista. Por um lado, porque, sem nem sequer se preocupar com isso, atiça o potencial fascista, que na Alemanha não diminuiu; mas, ao incubar em si mesmo essas tendências - e também nisso não concordamos - elas convergem imediatamente para o fascismo. Como sintoma dessas tendências indico a técnica de, convocando para discutir, tornar qualquer discussão impossível; a bárbara desumanidade de um comportamento regressivo que ainda por cima confunde regressão com revolução; o cego primado da ação; o formalismo, que se torna indiferente ao conteúdo e à forma daquilo contra o que se revoltam, a saber, a nossa teoria. (...) Dialética quer dizer, dentre outras coisas, que os fins não são indiferentes aos meios; o que acontece aqui mostra em detalhes como o apego burocrático a regulamentos, 'obrigações', a inúmeros grêmios e similares, adquire drasticamente os traços daquela tecnocratização, contra a qual querem supostamente se opor e contra a qual nós, de fato, nos opomos. (Adorno, CM. p. 13-14). ${ }^{18}$

Quando Adorno faz tal declaração, ele já tinha passado por ao menos três situações especialmente embaraçosas. A primeira foi quando um grupo de estudantes exigiu que Adorno suspendesse uma conferência sobre Goethe como forma de apoiar um ativista que havia sido preso (o grupo sustentava uma faixa irônica na qual estava escrito "os fascistas de esquerda de Berlin saúdam a Teddie, o classicista"). O segundo foi a invasão do Instituto de Pesquisas Sociais, em janeiro de 1969, que terminou com o apelo, por parte de Adorno, para a polícia desocupar o prédio e deter os manifestantes ${ }^{19}$. Por fim, em abril

18 Nos pontos 6, 7 e 8 das "Notas marginais sobre Teoria e Práxis", Adorno elenca e aprofunda a análise das tendências fascistas e autoritárias presentes no movimento estudantil da época, assim como na ApO.

19 Sem de modo algum tentar justificar a atitude de Adorno, a qual pode ser vista, no melhor dos casos, como indício de inaptidão para lidar com problemas práticos e situações conflituosas, é preciso levar em conta o contexto específico em que se deu a situação. Quanto a isso, é particularmente iluminadora a leitura da entrevista do aluno e biógrafo de Adorno, e um dos que participou da ocupação do Instituto em 1969, Detlev Claussen. Diz ele: "Sem dúvida a ocupação do Instituto foi a ação mais estúpida que fizemos. Em poucas situações pode aplicar-se com mais exatidão o conceito de 'ideia descabelada'. (...) Em minha opinião, Adorno compreendeu tudo perfeitamente: nosso movimento de greve se derrubava e precisávamos de algo novo; 'o fizeram porque estavam ficando sem alento, com fins propagandistas', disse então Adorno. (...) Não obstante naquele momento não tínhamos entendido todo o dramatismo da situação. Em nenhum momento levamos em conta sob que terrível pressão se encontrava Adorno e o Instituto. O então reitor da Universidade, Walter Rüegg, um sociólogo da Faculdade de Ciências Econômicas e Sociais, não era precisamente um amigo da Teoria Crítica. Havia submetido Adorno a uma pressão enorme e estava claro que lhe fariam responsável de tudo quanto pudesse passar durante a ocupação do Instituto. Assim podiam conseguir o término do apoio financeiro do Estado Federal de Hessen ao Instituto de Pesquisas Sociais, de modo que o modelo sociológico da Faculdade de Ciências Econômicas e Sociais ocupasse todo o terreno e a Teoria Crítica fosse erradicada da Universidade de Frankfurt. Mas não levamos em conta nada disso, comportamo-nos como uns ignorantes apolíticos. Só nos interessava a publicidade externa de um rebelde 'assassinato do pai', e isso funcionou bem" (Claussen, 2009, p. 119-120). 
do mesmo ano, ele foi impedido de ministrar uma aula e atacado por jovens semidesnudas, na última de uma série de interrupções que acabou por fazer com que desistisse do curso que estava ministrando.

\section{A práxis no tempo da teoria}

Na correspondência entre Marcuse e Adorno, há um diálogo bastante revelador sobre a posição e as divergências entre os dois teóricos. Na carta posterior à invasão do Instituto, aquele que permaneceu no exílio escreve ao que regressou: "sabemos (e eles sabem) que a situação não é revolucionária, nem sequer pré-revolucionária. Mas essa situação é tão horrível, tão sufocante e degradante que a rebelião contra ela obriga a uma reação biológica, fisiológica" (Marcuse, 1997, p. 8). Aquele que regressou responde:

A tua mais forte alegação consiste em dizer que a situação é tão horrível que se deve tentar quebrá-la, mesmo reconhecendo ser isso objetivamente impossível. Eu levo o argumento a sério. Mas considero-o falso. Nós, tu assim como eu, suportamos outrora uma situação muito mais terrível ainda, o assassinato dos judeus, sem que tivéssemos passado à prática, simplesmente porque nos era vedada. (Adorno, CM, p. 9)

O debate prossegue. Marcuse afirma então que a prática, impossível de ser levada a cabo na situação à qual Adorno se refere, então já "não nos é vedada. A diferença entre as duas situações é aquela que existe entre fascismo e democracia burguesa" (Marcuse, 1997, p. 11). Surpreendente é a resposta de Adorno, precisamente aquele que, neste caso específico, estava na posição de defensor da democracia existente: "Na tua opinião, a prática hoje, em sentido enfático, não nos seria vedada; a esse respeito, penso de maneira diferente. $\mathrm{Eu}$ deveria negar tudo o que pensei e sei sobre a tendência objetiva se quisesse acreditar que o movimento de protesto dos estudantes alemães tem qualquer probabilidade de atuar eficazmente na sociedade" (Adorno, CM, p. 13). Isto é, sem querer menosprezar ou atenuar as diferenças existentes entre o fascismo e a democracia burguesa, Adorno enfatiza que a possibilidade de atuar, de transformar de forma consciente, não é existente nem em uma situação nem em outra. Mas o que justifica tamanho ceticismo?

Em primeiro lugar, como já foi visto, o fato de que a emancipação estava objetivamente bloqueada. Em segundo, o caráter de certo modo ilusório da democracia; caráter este que era atacado pelos estudantes por seu autoritarismo latente e implícito, mas que era defendido pelo frankfurtiano por temor que esse autoritarismo deixasse de estar latente e se tornasse explícito, evidente. Ademais, a própria crítica da sociedade era então muito tímida ou incipiente, de modo que a bem-vinda não adesão dos jovens à tal sociedade, a resistência deles em adaptar-se a ela, tinha ainda um longo caminho a percorrer antes 
que tivesse a oportunidade concreta de transformá-la. No fundo, a oposição de certo modo intransigente de Adorno a certo engajamento revela a adoção da tese de que só em certos momentos históricos, por assim dizer excepcionais, as coisas se ajeitam de tal modo que a ação individual pode fazer alguma diferença, ou ao menos alguma diferença na própria estrutura da sociedade. Situações em que o próprio sistema, em virtude de suas contradições internas, gera uma tal instabilidade que se coloca ele próprio em uma posição que pode ser derrubado. De certa forma, era isso que ocorrera em meados do século XIX e que, salvo engano, não mais se deu depois de então.

Contudo, a recusa veemente a passar do plano da teoria para o da prática parece, à primeira vista, no mínimo niilista. Na verdade, fica-se aqui diante de uma aporia objetiva, talvez mesmo insolúvel: é preciso escolher entre, após uma rápida análise, recorrer a uma tentativa ilusória de transformação da sociedade ou, ao contrário, deter-se mais no momento teórico, fazendo uma análise de maior fôlego sobre a situação existente e perceber que qualquer tentativa prática de transformação radical está fadada ao fracasso de antemão. Ambas as escolhas parecem igualmente desesperadoras. Ademais, tanto a prática é inútil se ilusória quanto a teoria, se esta só consegue ensinar quão má é a situação em que o teórico se encontra ${ }^{20}$. Tampouco é preciso indagar sobre um possível caminho do meio, o qual, como afirmava Schönberg, certamente é o único que não conduz a Roma. Adorno, ao menos de certa forma, busca contornar o problema, (4.1) questionando a radicalidade da separação entre teoria e prática, (4.2) mostrando que mesmo uma atividade eminentemente teórica pode ter consequências reais e (4.3) atenuando este seu veredito sobre a inutilidade do ativismo.

\section{1 "Teoria é uma forma de práxis"}

A primeira forma de contornar a aporia objetiva recém-referida consiste no questionamento da cisão radical daquilo que é teoria e daquilo que é prática. Segundo Adorno:

20 Neste sentido, pode-se falar de uma aporia da própria realidade, pois vive-se uma situação que exorta sua transformação prática ao mesmo tempo que a impede, na qual a práxis é tanto urgente quanto inútil, como fica claro nesta passagem: "As perspectivas práticas são escassas. Sobretudo quem faz propostas converte-se facilmente em cúmplice. O discurso de um nós, com o qual se poderia identificar, já firma a cumplicidade com o mal e o engano de que boa vontade e a prontidão para atuar juntos poderia conseguir algo, onde aquela vontade é impotente e a identificação com os hommes de bonne volonté uma forma disfarçada do mau [Übels]. No entanto, a pura convicção que se nega a intervir do mesmo modo reforça aquilo que a aterroriza. A contradição não é apaziguada pela reflexão; ela é ditada pela constituição da realidade. Mas em um momento histórico no qual a práxis que diz respeito à totalidade parece truncada em todo lugar, mesmo as reformas modestas querem ganhar mais direito do que lhes convém." (Adorno, E, p. 458). 
Dever-se-ia formar uma consciência de teoria e práxis que não separasse ambas de modo que a teoria fosse impotente e a práxis arbitrária, nem destruísse a teoria por meio daquilo que Kant e Fichte proclamaram, o primado proto-burguês da razão prática. Pensar é um agir, teoria é uma forma de práxis; somente a ideologia da pureza do pensamento mistifica este ponto. O pensar tem um duplo caráter: é imanentemente determinado e é persuasivo [stringent] e obrigatório em si mesmo, mas, ao mesmo tempo, é um modo de comportamento real indispensável em meio à realidade. (Adorno, MzTP, p. 761)

Assim, ele afirma que é preciso rechaçar a aversão à teoria como se ela fosse algo inútil e desnecessário. Ao contrário, ela é também uma forma de práxis, de comportamento, e pode, por conseguinte, contribuir para futuras transformações. Poder-se-ia dizer que, em última instância, a cisão radical entre teoria e prática remete ao dualismo mente/corpo cartesiano ou aos dois mundos de Kant, não podendo ser válida em uma teoria dialética que vê no próprio mundo material, na medida em que ele é produzido ou transformado pelos humanos, também um produto do seu "espírito" (ou mesmo um produto da falta dele, da sua cegueira).

Em uma entrevista ao jornal Der Spiegel, em 1969, Adorno reafirma sua tese na forma de uma questão: “dever-se-ia uma vez questionar se não é também uma forma de se opor um homem pensar e escrever as coisas que escrevo. Não é portanto a teoria também uma forma genuína de práxis?” (Adorno, KAvE, p. 408). E, no momento em que um ativismo do tipo voluntário, que acredita que para as coisas mudarem basta um pouco de boa vontade e de trabalho, mostra sua completa incapacidade e inutilidade, não resta senão a teoria, por assim dizer, "pura", como forma de prática transformadora? Esta parece ser, novamente, a posição de Adorno, no final dos anos 1960 "Apesar de sua não-liberdade, a teoria é, em meio ao não-livre, o representante da liberdade" (Adorno, MzTP, p. 763). Isto é, no momento em que a liberdade está ausente, mesmo na prática teórica, é a teoria que a substitui e a representa. Embora também o teórico não deva nutrir ilusões sobre seu fazer, pois mesmo a teoria não é livre.

\subsection{Efeitos práticos da atividade puramente teórica}

$\mathrm{Na}$ mesma entrevista supracitada, Adorno é questionado sobre como se poderia mudar a totalidade social sem se recorrer a ações particulares. Sua resposta é a seguinte:

Não sei o que responder. A pergunta ‘que se deve fazer?' a maioria das vezes só posso responder: 'não o sei'. Só posso analisar sem inibições o que há. Então se me repreende: se exerces a crítica, também estás obrigado a dizer como se pode melhorar o criticado. Mas isto considero um preconceito burguês. Incontáveis vezes sucedeu na 
história que precisamente obras de intenção puramente teórica mudaram a consciência, e com isso também a realidade social. (Adorno, KAvE, p. 404)

Por conseguinte, fica claro que Adorno inverte aqui a primazia da prática sobre a teoria. Ele não só afirma que o ativismo voluntarista é completamente incapaz de transformar a realidade como diz que é preciso rever a ideia de que a teoria deve sempre estar diretamente relacionada com propostas concretas. Antes, é necessário perceber que é precisamente por seu rigor e objetividade, por sua capacidade de analisar corretamente determinada situação, que a teoria pode contribuir para a mudança ${ }^{21}$. Aliás, não cabe necessariamente à teoria oferecer alternativas para a situação criticada. Ela já é útil o suficiente se fizer boa análise da situação existente. Não se pode subordinar a teoria à prática de antemão, pois muitas vezes se viu que precisamente as teorias que não se subordinaram à prática, que não visavam a qualquer transformação imediata do mundo, conseguiram de certa forma transformá-lo. Na conclusão do artigo que escreveu exclusivamente a este respeito, as "Notas marginais sobre teoria e práxis", o autor afirma: "A relação entre teoria e práxis é, uma vez que elas se afastaram uma da outra, a de mudança qualitativa, não a de transição, muito menos a de subordinação. (...) A teoria que poderia ter mais esperança em se realizar é aquela que não está pensada como instruções para realizá-la" (Adorno, MzTP, p. 780). Ele recorda como mesmo a obra marxiana, que supôs, a certa altura, a unidade entre teoria e prática, não trata da questão das transições concretas; que mesmo $O$ Capital não contém um programa de ação ${ }^{22}$.

\subsection{Ativismo mínimo}

No entanto, mesmo a aversão de Adorno ao ativismo não deve ser considerada total. Em primeiro lugar porque ele despendeu grande parte de seu tempo em "intervenções", isto é, em aparições em veículos de massa como rádio,

21 Freyenhagen (Cf. 2014) observa que a defesa da teoria não subordinada à práxis é similar à defesa da arte que resiste ao engajamento político. Na visão do frankfurtiano, em especial como é desenvolvida na Teoria estética, é a arte mais rigorosa e que mais se entrega à sua própria finalidade, ao desenvolvimento da forma, como aquela de Kafka, Beckett ou Schönberg, que contribui para manter viva a esperança de um mundo melhor, e não a arte que tenta se engajar diretamente na transformação social ao custo de seu rigor e de sua autonomia.

22 Por isso é problemática a afirmação de Habermas de que a teoria adorniana caracteriza-se por uma "insistência na contemplação", de que é "uma teoria apartada da práxis" (Habermas, 2012, p. 659) tal como fora a tradição da grande filosofia, assim como é problemática a (consonante) afirmação de Krahl de que "ao se mover para cada vez mais longe da práxis histórica, a teoria crítica de Adorno retrocede a formas tradicionais de contemplação" (Krahl, 1975, p. 834). Embora insista na teoria, ele a pensa como uma forma de comportamento crítico, de intervenção, algo totalmente distinto da forma como a teoria foi comumente compreendida no pensamento filosófico (embora nem sempre, pois os teóricos do esclarecimento sempre viram na teoria uma forma eficaz de intervenção). Ela propõe antes uma diluição da fronteira entre teoria e práxis do que uma forma de teoria apartada da práxis, como Habermas e Krahl sugerem. 
televisão e jornais de grande tiragem ${ }^{23}$. Nos seus últimos anos, quando já era um teórico com certo renome, ele exerceu a função que se pode designar por "intelectual público". Se é certo que nunca propôs um programa de ação, suas aparições ajudavam então a disseminar o sentimento de insatisfação social e, principalmente, o questionamento sobre as causas dessa insatisfação. Sua participação crítica nestes veículos certamente fomentava o processo de autorreflexão e autocrítica, precisamente o processo cuja ausência quase completa era tão denunciada pelo frankfurtiano.

Em segundo lugar, Adorno participou ativamente de algumas mobilizações e protestos. Ele lutou pela democratização da universidade alemã; contra as leis de emergência e contra todas as formas de antissemitismo (inclusive, neste caso preciso, escrevendo algo que até pode ser considerado um programa de ação: "Sobre o combate ao antissemitismo hoje" [Adorno, ZBAh, p. 360383]). Fica claro, portanto, que ele não recusou o ativismo como tal, mas somente certas formas de ativismo (diz ele, na já citada entrevista: "Participei nas manifestações contra as leis de emergência e fiz tudo o que pude no âmbito da reforma do direito penal. Mas há uma diferença fundamental entre fazer estas coisas e me lançar a uma práxis que é pouco menos que ilusória e jogar pedras contra institutos universitários" [Adorno, KAvE, p. 406]). Se não era possível então emancipar-se do capitalismo, mesmo assim se poderia lutar para que a universidade e a sociedade fossem mais democráticas, algo que poderia ser conseguido. No entanto, é preciso salientar que uma luta não substitui a outra. Não é porque a sociedade pode se tornar mais democrática que o capitalismo deve deixar de ser criticado e a sua abolição, almejada - até mesmo porque, para Adorno, uma sociedade capitalista nunca será realmente ou plenamente democrática (algo que distingue claramente Adorno da maior parte das assim chamadas segunda e terceira geração de teóricos críticos, sobretudo do Habermas posterior à Teoria da ação comunicativa).

Adorno deixa claro que é preciso se engajar no processo de desbarbarização da sociedade, que é preciso fazer tudo o que for possível para que certos eventos nefastos de triste memória não voltem a se repetir, nem nada que possa se assemelhar a eles. Para um autor como ele, que pensa que aquilo que fez Auschwitz possível segue latente na sociedade, isso não é pouca coisa. Ao examinar o que é possível fazer, ele afirma que, "como a possibilidade de mudar os requisitos objetivos, a saber, os sociais e políticos, que contribuem para esses acontecimentos está muito limitada hoje, as tentativas de impedir a

23 Pickford afirma que "incompleta documentação indica que somente durante o período entre 1950 e 1969 Adorno participou em mais do que 180 programas de rádio. (...) Mais do que dois terços dos programas do pós-guerra foram devotados a tópicos não musicais, incluindo assuntos de teoria crítica da sociedade, educação e política contemporânea" (Pickford, 2002, p. 328). O autor informa ainda que Adorno participou, no mesmo período, de ao menos trinta programas televisivos. 
repetição se reduzem necessariamente ao aspecto subjetivo" (Adorno, EnA, p. 675-676). Isto é, mesmo que efetivamente não tenhamos condições de alterar a situação social e política, garantindo a inexistência das condições objetivas de tais acontecimentos, é possível se engajar na transformação das condições subjetivas. Significa, por conseguinte, engajar-se na reforma educacional para que ela vise à autorreflexão crítica, à autonomia. Aliás, engajar-se em todos os âmbitos em que a autonomia pode ser ampliada, pois "a única efetiva força contra o princípio de Auschwitz seria a autonomia, se posso empregar este termo kantiano; a força da reflexão, da autodeterminação, da não-colaboração" (Adorno, EnA, p. 679). Mais do que isso, lutar para que a educação não reprima o medo e incentive a dureza, que esta não ensine a ser indiferente diante do sofrimento alheio (Cf. Adorno, EnA, p. 682-683). Portanto, pode-se dizer que embora Adorno não acredite na possibilidade de uma práxis emancipadora na situação atual, ele advoga claramente um engajamento na resistência à desumanização total.

A questão que fica em aberto é se esta práxis contra a barbárie efetivamente consiste apenas em uma resistência ou se ela mesma não contém elementos emancipatórios. Se lutar para que o pior não volte a acontecer pode ser também um meio de se chegar a uma situação melhor. Se mudanças subjetivas exitosas não conduzem, em longo prazo, necessariamente também a transformações objetivas. Esta é uma questão espinhosa e vejo poucas evidências textuais para justificar uma interpretação. No entanto, gostaria de formular uma hipótese, a qual, a meu ver, está de acordo com o texto adorniano, muito embora nunca apareça de forma explícita. Minha sugestão é que é preciso diferenciar um comportamento de resistência de uma prática libertadora; modos de atenuar e remediar os sintomas do combate efetivo à doença. Ambos os momentos são necessários e igualmente importantes. No entanto, para Adorno, na sociedade na qual ele vive, toda prática libertadora e todo combate à doença estão fadados ao fracasso, ao menos até que algo de objetivo mude. O que se pode, neste âmbito, é seguir fazendo a melhor análise possível do existente, seguir teorizando sobre as suas contradições estruturais para, quando algo de objetivo mudar e a possibilidade de uma libertação novamente ocorrer (como teria sido o caso na década de 40 do século XIX), haver uma teoria crítica suficientemente desenvolvida apta a contribuir com tal libertação, capaz de dizer, por exemplo, do que é preciso se libertar e a se contrapor a toda forma de pseudolibertação que elege bodes expiatórios como raízes dos males, o que pode tanto frustrar a libertação quanto mesmo conduzir a mais barbáries. Eis a ideia da teoria crítica como garrafas jogadas ao mar, na esperança de que futuras gerações as recolham e façam bom uso dela. Porém, isso não conduz a um comodismo diante das lutas que podem ser travadas naquele preciso momento e naquela precisa 
sociedade. Se a vida no capitalismo não pode ser uma vida correta, ela pode, contudo, ser uma vida menos errada (sigo, aqui, a sugestão de Freyenhagen [cf. 2013]). Há diversos graus de quão ruim uma sociedade pode ser. Neste caso, é preciso resistir aos processos que conduzem a sociedade às piores situações, lutar para que a autonomia se mantenha ao menos em certas esferas. Sem isso, aliás, mesmo a mudança futura se tornaria cada vez mais improvável.

\section{Conclusão}

Para resumir, foi visto neste artigo que, na visão de Adorno: 1) aquilo que impede a emancipação é o capitalismo; 2) por causa da integração do proletariado e da intensificação da dominação não há mais, ao menos por enquanto (isto é, anos 1960, sobretudo no continente europeu), condições objetivas para o êxito de uma transformação libertadora, de emancipação; 3 ) neste caso resta, para aqueles que querem transformar o mundo, um refúgio no trabalho teórico, ao menos até que voltem a existir condições objetivas para uma luta emancipatória; 4) o trabalho teórico capaz de salvaguardar a esperança de um mundo livre é aquele que não se subordina imediatamente à prática, mas que se abandona justamente à análise, o mais rigorosa possível do que há; 5) este diagnóstico não leva a um comodismo diante de certas lutas específicas, de resistência, que almejam que o pior não ocorra ou mesmo que pequenas melhorias possíveis dentro da atual situação social, isto é, do capitalismo, se deem.

Destarte, pode-se dizer que Adorno adota uma postura reformista e advoga pela defesa dos aperfeiçoamentos possíveis de serem obtidos dentro da ordem existente ${ }^{24}$, embora ele mesmo reconheça os limites de tal atitude. De qualquer forma, a opção por reforma ou revolução não deveria dizer respeito a preferências pessoais do autor, mas sim ao seu próprio diagnóstico e às perspectivas de transformação possíveis indicadas por ele. Num momento em que a transformação radical da sociedade não é cogitável, ainda que desejável, não resta alternativa senão buscar aquilo que pode, então, ser feito:

Eu diria que (...) quanto mais a estrutura social presente tem o caráter de uma 'segunda natureza' terrivelmente aglomerada, em certas condições as mais modestas intervenções na realidade vigente possuem um significado, poderíamos dizer até mesmo simbólico, muito maior do que efetivamente lhes corresponderia. Assim penso que na realidade social vigente deveríamos ser muito mais parcimoniosos com as críticas ao chamado reformismo do que era possível no século XIX e no começo do século XX. A posição diante das reformas em certo sentido é função de como avaliamos as relações estruturais

24 "Minimizar, por causa da estrutura do todo, a possibilidade de aperfeiçoamento no âmbito da sociedade vigente, ou até mesmo - o que não faltou no passado - marcá-los como negativos, seria uma abstração idealista e danosa. Pois nisso expressar-se-ia um conceito de totalidade sobreposto aos interesses dos homens individuais que vivem aqui e agora, a requerer uma espécie de confiança abstrata no curso da história do mundo de que, ao menos nessa forma, sou incapaz" (Adorno, IS, p. 98). 
no âmbito do todo, e como hoje essa transformação do todo já não parece possível na mesma imediatez em que aparecia em meados do século XIX, também essas questões se deslocam a uma perspectiva inteiramente diferente. (Adorno, IS, p. 98-99)

Fica claro, com isso, que Adorno não pode ser considerado um teórico resignado, que sua teoria não pode ser reduzida a um mero lamento sobre quão mal é o mundo e de quão inevitável é tal maldade. Muito embora ele sustente um diagnóstico bastante sombrio sobre a sociedade em que viveu, um diagnóstico que diz tanto que tal mundo não é livre, quanto que a liberdade não está no horizonte das possibilidades de um futuro próximo, ele defende uma postura teórica crítica que mantém viva a lembrança de que o atual estado do mundo é fruto da própria cegueira dos homens e que tal estado, do mundo e da cegueira, pode ser superado.

Com isso espero ter contestado as críticas, ou melhor, o juízo de Lukács, Habermas e Kolakowski. No entanto, gostaria ainda de traçar uma rápida observação sobre tais vereditos. Apenas para dizer que se determinada teoria chega a conclusões desesperadoras, isto não diz nada sobre sua verdade ou falsidade. Objetivamente, uma situação pode ser desesperadora. Um doente, por exemplo, pode estar entrando na fase terminal de uma doença incurável. Uma sociedade, igualmente. O teórico que, por chegar a tal conclusão, abandona sua teoria para não fazer "terra arrasada" e parte em busca de indícios emancipadores pode bem conseguir iludir a si mesmo, mas não fará boa teoria. Igualmente aquele que deixa de criticar o capitalismo simplesmente por não acreditar que seja possível sua superação faz da necessidade virtude, mas a situação não se torna melhor por causa disso. Uma situação não passa a ser melhor ou mesmo desejável por não se ter como fugir dela. Pelo contrário, isso só ressalta a ausência de liberdade nela. Neste quesito, Adorno já faz a crítica avant la lettre de seus críticos: se uma teoria pode contribuir, de alguma forma, para a emancipação, não é a que se subordina à prática, tampouco a que muda seu diagnóstico para não chegar a conclusões desesperançadas, mas sim aquela que analisa o que há, da forma mais rigorosa possível, mesmo que chegue aos piores diagnósticos ${ }^{25}$. De qualquer forma, é só com um diagnóstico preciso de

Para não suscitar dúvidas, esclareço minha interpretação: discordo dos autores (Habermas, Lukács e Kolakowski) por verem a teoria adorniana como resignada, uma vez que, como sugiro, tal teoria não defende "uma aceitação sem revolta dos sofrimentos da existência" (Houaiss, 2009), mas, pelo contrário, se engaja em uma resistência aos processos de desumanização, assim como mantém acesa a esperança de engajamento futuro em processos realmente emancipatórios. Por outro lado, estou de acordo com eles na afirmação de que a teoria do frankfurtiano é pessimista, mas, ao contrário deles, não penso que isso seja um problema teórico, senão a conclusão coerente de suas análises e observações. Neste sentido, criticar de pessimista uma teoria é uma espécie de diversionismo: importa unicamente saber se suas conclusões pessimistas derivam de análises corretas. Se o diagnóstico for bem feito, não há que se lamentar a teoria por ter chegado a tais conclusões, mas sim a realidade por impor tal pessimismo ao pensamento rigoroso. Ou, como diz Schwarz, "o bloqueio da solução revolucionária e a esterilidade da política eleitoral são diagnósticos, e não preferências. Pode-se discordar, mas as razões para concordar são consideráveis" 
determinada situação que se pode superá-la, ao menos se esta se quiser consciente, e não a continuação da sempre existente cegueira.

\section{Referências:}

ADORNO, Theodor W. (GR). Graecullus. In: Frankfurter Adorno Blätter VIII. Frankfurt am Main: Text und Kritik, 2003. (pp. 9-41).

. (KTP). "Kritische Theorie und Protestbewegung". In: Gesammelte Schriften. Frankfurt am Main: Suhrkamp Verlag, 1986. (20 volumes)

. (DN). "Dialética negativa". Tradução de M. A. Casanova. Revisão de E. S. Neves Silva. Rio de Janeiro: Zahar, 2009.

. (WnP). Wozu noch Philosophie. In: Gesammelte Schriften. Frankfurt am Main: Suhrkamp Verlag, 1986. (20 volumes)

. (VüND). "Vorlesung über Negative Dialektik". Frankfurt am Main: Suhrkamp Verlag, 2003.

. (PETG). "Philosophische Elementer einer Theorie der Gesellschaft". Frankfurt am Main: Suhrkamp Verlag, 2008. 2008.

. (IS). "Introdução à sociologia". Tradução de W. Leo Maar. São Paulo: Unesp,

. (MzTP). "Marginalien zu Theorie und Praxis". In: Gesammelte Schriften. Frankfurt am Main: Suhrkamp Verlag, 1986. (20 volumes)

. (Me). "Metaphysik. Begriffe und Probleme". Frankfurt am Main: Suhrkamp Verlag, 1998.

. (SoI). "Spätkapitalismus oder Industriegesellschaft". In: Gesammelte Schriften). Frankfurt am Main: Suhrkamp Verlag, 1986. (20 volumes

. (SRh). "Sexualtabus und Recht heute". In: Gesammelte Schriften. Frankfurt am Main: Suhrkamp Verlag, 1986. (20 volumes)

. (CM). "Marcuse-Adorno: as últimas cartas". In: Correspondência MarcuseAdorno: As últimas cartas. In: Praga, n. 3, pp. 7-17, 1997.

. (E). "Eingriffe". In: Gesammelte Schriften. Frankfurt am Main: Suhrkamp Verlag, 1986. (20 volumes)

. (KavE). In: Keine Angst vor dem Elfenbeinturm. Gesammelte Schriften. Frankfurt am Main: Suhrkamp Verlag, 1986. (20 volumes)

. (ZBAh). In: Zur Bekämpfung des Antisemitismus heute. Gesammelte Schriften. Frankfurt am Main: Suhrkamp Verlag, 1986. (20 volumes)

. (EnA). In: Erziehung nach Auschwitz. Gesammelte Schriften. Frankfurt am Main: Suhrkamp Verlag, 1986. (20 volumes)

BLASCO, J. M. "Elementos para la reapropiación de la Teoría Crítica de Theodor W. Adorno". Salamanca: Ediciones Universidad de Salamanca, 2010.

CLAUSSEN, Detlev. "Theodor W. Adorno: One Last Genius". Cambridge, London: Harvard University Press, 2008.

. "Teoría crítica y experiencia viva". Constelaciones: Revista de Teoría Crítica, 
n. 1, pp. 105-159, 2009.

COOK, Deborah. "Adorno, Habermas and the search of a rational society". Londres: Routledge, 2004.

"Ein reaktionäres Schwein? Political Activism and Prospects for Change in Adorno". Revue internationale de Philosophie, n. 227, pp. 47-67, $2004 \mathrm{~b}$.

DUARTE, Rodrigo. "Adornos. Nove ensaios sobre o filósofo frankfurtiano". Belo Horizonte: UFMG, 1997.

FREYENHAGEN, Fabian. “Adorno's Practical Philosophy: Living Less Wrongly”. Cambridge: Cambridge University Press, 2013.

“Adorno's Politics. Theory and Praxis in Germany's 1960s". Philosophy and Social Criticism, v. 40, n. 9, pp. 867-893, 2014.

HABERMAS, Jürgen. "Teoria do agir comunicativo". Tradução de P. A. Soethe e F. B. Siebeneichler. São Paulo: Martins Fontes, 2012.

HOUAISS, Antônio. "Dicionário eletrônico Houaiss da Língua Portuguesa 3.0". São Paulo: Objetiva, 2009.

HULLOT-KENTOR, Robert. "Things beyond resemblance: On Theodor W. Adorno". New York: Columbia University Press, 2006.

JAPPE, Anselm. "Crédito à morte". Tradução de R. J. F. de Oliveira. São Paulo: Hedra, 2013.

JUÁREZ, Esteban A. "Th. W. Adorno: El elogio de la teoría y la impaciencia de la praxis”. Signos filosóficos, v. XIV, n. 27, pp. 89-118, 2012.

KOLAKOWSKI, Leszek. "Main currents of Marxism". Vol. III: The Breakdown. Trad. P. S. Falla. Oxford: Oxford University Press, 1978.

KRAHL, Hans-Jürgen. “The Political Contradiction in Adorno's Critical Theory”. The Sociological Review, n. 23, pp. 831-834, 1975.

LUKÁCS, Georg. "Prefácio" (1962). In: LUKÁCS, G. "A Teoria do romance”. Tradução de J. M. M. de Macedo. São Paulo: Duas Cidades; Ed. 34, 2000.

MARCUSE, Herbert. "Correspondência Marcuse-Adorno: As últimas cartas". Praga, n. 3, pp. 7-17, 1997.

MARX, Karl. Ad Feuerbach (1845). In: . "A Ideologia alemã”. Tradução de R. Enderle; N. Schneider; L. C. Martorano. São Paulo: Boitempo, 2007. MÜLLER-DOOHM, Stefan. "Adorno: A Biography". Malden, Cambridge: Polity Press, 2009.

PETRY, Franciele B. “Além de uma crítica à razão instrumental”. Tese (Doutorado em Filosofia). Universidade Federal de Santa Catarina, 2011.

PICKFORD, Henry W. "The Dialectic of Theory and Praxis: On Late Adorno". In: GIBSON, N.; RUBIN, A. “Adorno: A Critical Reader”. Oxford: Blackwell, 2007. (pp. 312-340).

PIKETTY, Thomas. "O Capital no século XXI". Tradução de Mônica Baumgarten de Bolle. Rio de Janeiro: Intrínseca, 2014.

RYAN, Alan. "The Power of Positive Thinking". The New York Review of Books, $\mathrm{n}$. 16 January, 2003.

SCHWARZ, Roberto. "Sobre Adorno". In: . "Martinha versus Lucrécia: ensaios e entrevistas". São Paulo: Companhia das Letras, 2012. (pp. 44-51). 
SILVA, Eduardo S. Neves. "Mímesis e forma: a crítica de Habermas a Adorno (e uma resposta)". In: DUARTE, R.; FIGUEIREDO, V.; KANGUSSU, I. (Org.). "Theoria Aesthetica". Porto Alegre: Escritos, 2005

WILDING, Adrian. "Pied Pipers and Polymaths: Adorno's Critique of Praxisism". In: HOLLOWAY, J.; MATAMOROS, F.; TISCHLER, S. "Negativity and Revolution. Adorno and Political Ativism”. Londres: Pluto Press, 2009. 